\title{
An Empirical Investigation on Tourism Attractive Destinations and Spatial Behavioral Tourist Pattern Analysis in Tehran
}

\author{
Ali Movahed ${ }^{1}$ and Kamran Jafarpour Ghalehteimouri ${ }^{2^{\star}}$ \\ ${ }^{1}$ Department of Geography and Tourism Planning, Faculty of Geography, \\ Kharazmi University, Iran. \\ ${ }^{2}$ Kharazmi University, Iran.
}

Authors' contributions

This work was carried out in collaboration with author $A M$ and he gave the idea and we together started to do this research based on Tehran tourism resources distribution and tourism spatial behavior. Both authors read and approved the final manuscript.

Article Information

DOI: 10.9734/AJGR/2020/v3i130097

Editor(s):

(1) Dr. Armando García Chiang, Professor, Departamento de Sociología, Universidad Autónoma Metropolitana- Iztapalapa,

(1) Ibrahim, Oladayo Ramon, Lagos State Polytechnic, Nigeria. (2) Ahmad Albattat, Management and Science University, Malaysia.

(3) Sultan Sevinç Kurt Konakoglu, Amasya University, Turkey. Complete Peer review History: http://www.sdiarticle4.com/review-history/53347

Case Study

Received 22 October 2019

Accepted 27 December 2019

Published 18 January 2020

\begin{abstract}
Cities are important tourist destinations and tourism has affected the urban environment. Urban tourism space is where tourism resources are located. The behavioural pattern of tourists also subordinates of tourism resources. Therefore, behavioural geography explains the spatial patterns of the behaviour of tourists as a cognitive-perceptual process. The behavioural school has attended to areas such as mental maps of behaviour, spatial behaviour of tourism, and perception of the environment. The main objective of this research is identifying the spatial behaviour of tourists in Tehran. The research method is descriptive-analytic and used secondary data, which are available in different reports, drafts, and related institutes and questionnaire to collect the research data. The research results show that the behaviour pattern of foreign tourists depends on tourism resources. These tourism resources are located in the central part of Tehran. In addition, the south entrance of the city (Imam Khomeini airport) is the most important entrances for foreign tourists and
\end{abstract}


transporting pattern is from the south to the centre and north of Tehran. Since Tehran city has located between ways so stopping time is short in this city. In other words, visiting the city's attractions has focused on the type of historical-cultural tourism in the central part of Tehran.

Keywords: Spatial pattern; urban space; tourist destinations; spatial behavior; Tehran.

\section{INTRODUCTION}

The number of people who take a trip from one point in this world to the other side of the world is significant. These people do not carry themselves as a person; indeed, they are causes of many changes in the destination point and in the world. In 2011 and for the first time the tourism industry makeover USD 1,030 billion. "The total contribution of Travel \& Tourism to GDP (including wider effects from investment, the supply chain and induced income impacts, was USD8,811.0bn in 2018 (10.4\% of GDP) and is expected to grow by $3.6 \%$ to USD9,126.7bn (10.4\% of GDP) in 2019.

It is forecast to rise by $3.7 \%$ pa to USD13,085.7bn by 2029 (11.5\% of GDP) (WTTC, 2019). Therefore, geography has the most contribution to the tourism industry and it seems there is a high correlation between geography and tourism. The tourism geography is the very sophisticated topic in geography and it is combined with theoretical and conceptual research and as a result of both of them, an applied study [1,2]. The tourism destination attraction has been an important issue in urban tourism studies [3] which is the cause of many negative and positive is impacts. Ignoring all tourism effective factors in urban planning endangers the success of tourist travel by affecting on travel quality [4]. This considerable part of travel is those spaces that tourist is willing to visit if any physical or human barriers cause the tourist does not reach to the destination that is meant the failure of urban tourism planning. However, there are many efforts to understand the causes and realities between tourist and the destination source (e.g., cognitive maps with different perceptual themes were visualized according to photos) [5]. The spatial pattern of tourist destinations in urban landscape may have various pattern, which forms under the certain spatial process at the given time and space [6]. The tourism industry is not what it looked or applied in years ago many factors involve making a tourism industry different. As technology is improving the relevant sectors to tourism industry (e.g., IT, road, sea, and air transportation) the tourism industry and application has been being improved by all these scientific and human advancements. Therefore the meaning and concept of the time and space have changed [7]. Destination attraction rely on quality of flexibility, functional diversity, physical diversity, vegetation, safety, lightening, landscape attractiveness, identity, and memorability in relation to the urban space, and social and arbitrary activities. Tourism is a geographic phenomenon that focuses on the people movements, goods and services over time and places, and their focus is on providing a good understanding of the patterns of tourism activities. There is not very well documented research based on analysis of the behavioural patterns of tourists or some case studies of geographic analysis relation between tourism destination and imagination [8], students imagination [9], tourism responsibility [10]. Planning for the development of tourism activities begins by understanding the nature and patterns of tourism behaviour (Ziaee and Ahmadi, 2012). Generally, cities are where the tourist enters to a country and that is so important to understand what kinds of goods and services the city offers to the tourist and creates their behaviour. The relation between what tourists have made in his/her mind and tourist destination in the city draws the pattern of the tourist spatial behavioural pattern. The distribution attractive tourist places in the city will provide a clear understanding to know what is more interesting for tourists [11]. Knowing of the tourists movement in urban space, the number of tourists and in what period of time, and to which parts of the city are going, makes a pattern like their footprint of in a snowy day showing their path of movement in urban spaces. The location of tourism infrastructure and planning provide tourism services and facilities, the provision of walkways for walking and providing areas with a beautiful view that they need for awareness of the pattern of behaviour of tourists. Culture is an effective criteria in behavioural patterns, and behavioural patterns determine and illustrate how people use tourist spaces. Hence, in tourism psychology, the behaviour of the tourists and the causes and motivations that determine these behaviours are studied [12]. The purpose of this study is to identify and review the behaviour patterns of tourists in Tehran and to map the 
space travel of tourists and discover the dominant spatial patterns in Tehran's urban spaces [13]. By recognizing the pattern of the spatial behaviour of tourists, we are looking for factors influencing the formation of this pattern. Which of the tourism resources has a greater role in the tourism pattern of Tehran? Discuss the circulation routes and spaces used by tourists in relation to the spatial structure of the city of Tehran from a spatial perspective. The tourism spatial pattern analysis is key to have a better plan in urban areas [14]. Accurate research about tourism travel pattern in city links to the most visited tourist areas which is very helpful for national and regional tourism planning. Tourist has a desire to see some specific places, which are very common among tourists [15] based on climate, latitude, altitude, cultural, social, economic, and geographical features the tourists show interest and create different routes in the city. After the revolution in Iran, the previous spaces (e.eg. bar, clubs, discos, and casino) in the city are dead and there is a heavy restriction on alcohol and drugs. The tourist spatial behaviour pattern in the city has changed and they are looking for the cultural and socioeconomic side of tourism [16].

\section{COMMON PERSPECTIVES AND THEORIES}

Mobility of phenomena in space is carried out in the name of exchange, deformation, conversion, which represents the flow of raw materials, energy, movements and displacement of population, capital and tourists, and so on. Basically, communication patterns and urban currents are the creators of the dynamics of the structure and organization of space. Urban tourism is creating its own spatial behavior pattern, including the influential currents in space and space organization of the city [17]. In the field of space tourism, tourism refers to a sequence of attractions visited by tourists in geographic space and a sequence of movements in that geographic space from attraction to gravity [18]. The behavior of the tourists' space can be examined at different geographical levels. However, the number of criteria that will involve in different level of decision-making is different. The degree of importance and influence of each criterion will change due to the scale. Researchers and urban planners consider the spatial behavior of tourists as a discrete range of movements between stops and tourist sites [19]. Behaviorism and the emergence of the

Table 1. Negative and positive sociocultural effects of tourism

\begin{tabular}{|c|c|c|}
\hline Effective factors & Positive impacts & Negative impacts \\
\hline $\begin{array}{l}\text { Using culture as an } \\
\text { attraction }\end{array}$ & $\begin{array}{l}\text { - Increase of supporting the } \\
\text { traditional culture. } \\
\text { - Introducing the ethnic } \\
\text { identity. } \\
\text { - Revival the traditional arts } \\
\text { and rites. } \\
\text { - Revival the local language } \\
\text { and literature }\end{array}$ & $\begin{array}{l}\text { - Changes in the traditional arts due } \\
\text { to the tourists' tastes } \\
\text { - Influencing the privacy of } \\
\text { traditional areas } \\
\text { - Crowdedness in the traditional } \\
\text { place } \\
\text { - Commercialization of the cultural } \\
\text { products }\end{array}$ \\
\hline $\begin{array}{l}\text { Direct contact between } \\
\text { tourists and local } \\
\text { people }\end{array}$ & $\begin{array}{l}\text { - Reduction of the negative } \\
\text { behavioral representations } \\
\text { - Increase of the social } \\
\text { opportunities }\end{array}$ & $\begin{array}{ll}\text { - } & \text { Reinforcement of the negative } \\
\text { behavioral representations } \\
\text { - } & \text { Outbreak of new diseases } \\
\text { - Increase of the population density } \\
\text { and crowdedness }\end{array}$ \\
\hline $\begin{array}{l}\text { Changes of social } \\
\text { roles and jobs }\end{array}$ & $\begin{array}{l}\text { - Emergence of new jobs } \\
\text { - Reduction of social inequities }\end{array}$ & $\begin{array}{ll}- & \text { Increase of social conflicts } \\
- & \text { Increase of social inequities } \\
\text { - } & \text { Destruction of local languages } \\
& \text { and accents } \\
\end{array}$ \\
\hline $\begin{array}{l}\text { Development of } \\
\text { tourism bodies }\end{array}$ & $\begin{array}{l}\text { - Increase of recreational } \\
\text { facilities } \\
\text { - Increase of the accessibility } \\
\text { facilities }\end{array}$ & $\begin{array}{l}\text { - Limitedness of the local people's } \\
\text { accesses } \\
\text { - } \quad \text { Increase of the bureaucracy }\end{array}$ \\
\hline $\begin{array}{l}\text { Population increase } \\
\text { due to the tourism } \\
\text { development }\end{array}$ & $\begin{array}{l}\text { - Increase of the quality and } \\
\text { quantity of welfare facilities } \\
\text { - Increase of the quality of life }\end{array}$ & $\begin{array}{l}\text { - Increase of the crowdedness and } \\
\text { population mix } \\
\text { - } \quad \text { Increase of the crimes }\end{array}$ \\
\hline
\end{tabular}


geographic school of spatial behavior in 1952, is with the link between geography and the Gestalt Psychology School were developed by William Kirk. He believed that "what we need in our thoughts so that we can cover nature and humanity under a scientific discipline can only be achieved by adopting the Gestalt psychology field. In fact, after the introduction of geography into the Gestalt School of Psychology studies, the spatial perspective in geography was recognized as the Space Behavior School [20], (Farid, 2001). In terms of spatial, tourism is a kind of mobility between the source and destination of the link between tourism supply and demand. The quality of this is where indicators such as safety, speed and travel costs (Akbari, 2015) measure the space. Cities as one of the major tourist destinations are among the new phenomena that underlies a range of social, cultural and economic behaviors with regard to urban characteristics. One of the phenomena that affect the city's spatial patterns is urban tourism. Tourism is carried out within the framework of certain spatial patterns. Urban areas are often considered as important volunteering destinations due to historical and cultural attractions. Cities usually have diverse attractions such as museums, monuments and historic sites attracting many tourists (Hall, 2001). The behavioral pattern of tourists in the city is a function of urban spatial patterns that are defined as attraction, urban services, and social and economic communication [7]. Each spatial pattern is the result of human decisions; of course, the decisions and functions of man are related to the type of perception of being, thought, belief, institutions, and the structure of society and their needs [7].

Fig. 1 shows how is the relation between the tourist spatial behavior pattern and the type of locations that tourists prefer to visit. If the tourist destination were spattered in different places in the city, it will be like a point pattern. If the points queue up on a line and they stand back to back it will be like line patterns. At the end is a tourist when a tourist looks for an area to visit (e.g. park, or specific urban area) which are not like a point on the map they will form area patterns.

The spatial behavior of people is largely influenced by the mental images of the environment. The environmental structure greatly affects the orientation of people among buildings - neighborhoods, and cities. The path to some environments is easier than in other environments. Social and psychological aspects of navigation are important factors in the sense of individual security. (John Lang, 2011). Each travel destinations has a specific weight in the tourist mind. Geographically, even in the most biodiversified places in the world the human involvements can create a different perspective and feature and attract the different number of people. Human involvement in environment and city spaces can cause a positive spatial autocorrelation of the locations, which are tourist destinations. What the city spaces provide for visitors is due to the ecological spatial processes (e.g., species dispersal, competition for space and resources) or by spatial dependence due to (positive or negative) species responses to underlying environmental conditions [21]. The ecological foundations in different scales make different spatial behavior pattern it can be described with the interaction between structure and functioning [22]. Spatial structure due to the ecological spatial processes and spatial dependence affects spatial statistics, landscape metrics, and statistical modeling of the speciesenvironment correlation [21].

Fig. 2 shows the factors influencing the behavior pattern of tourists. Motivational factors for starting a trip, effective factors during travel and factors affecting the tourist after the trip. The ability of a tourist to understand a destination and choose what activities to do "is very personal". Of course, the issue to be addressed is external influences and the advice of those who speak with us on this travel destination can have a great influence on the behavior of the tourist (Fodness \& Brian 1997). According to Seaton et al., Understanding the reputation of a destination represents another set of tourist movements that affect these kinds of behaviors. (Seaton, Bennett et al., 1996). Although placing an attraction in a hierarchy of the places is often based on the ability to generate demand from that attraction (Christaller, 1963), and is effective on the spatial pattern of the destination. There are many social and economical issues involve to make/change the tourist mind about the tripe and increase or reduce the tripe time (Fig. 2).

\subsection{Hypotheses}

A. The spatial behavior pattern of tourists in Tehran is tourism resources functions (e.g. attractions, hotels, restaurants, etc.).

B. The spatial behavior pattern of tourists in Tehran is regular and follows a linear pattern. 


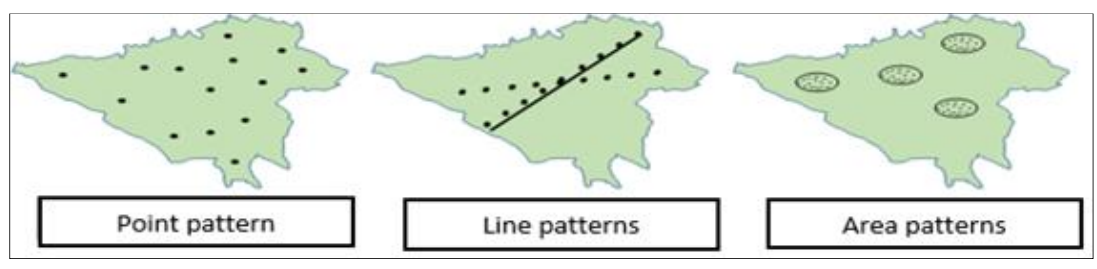

Fig. 1. Spatial pattern

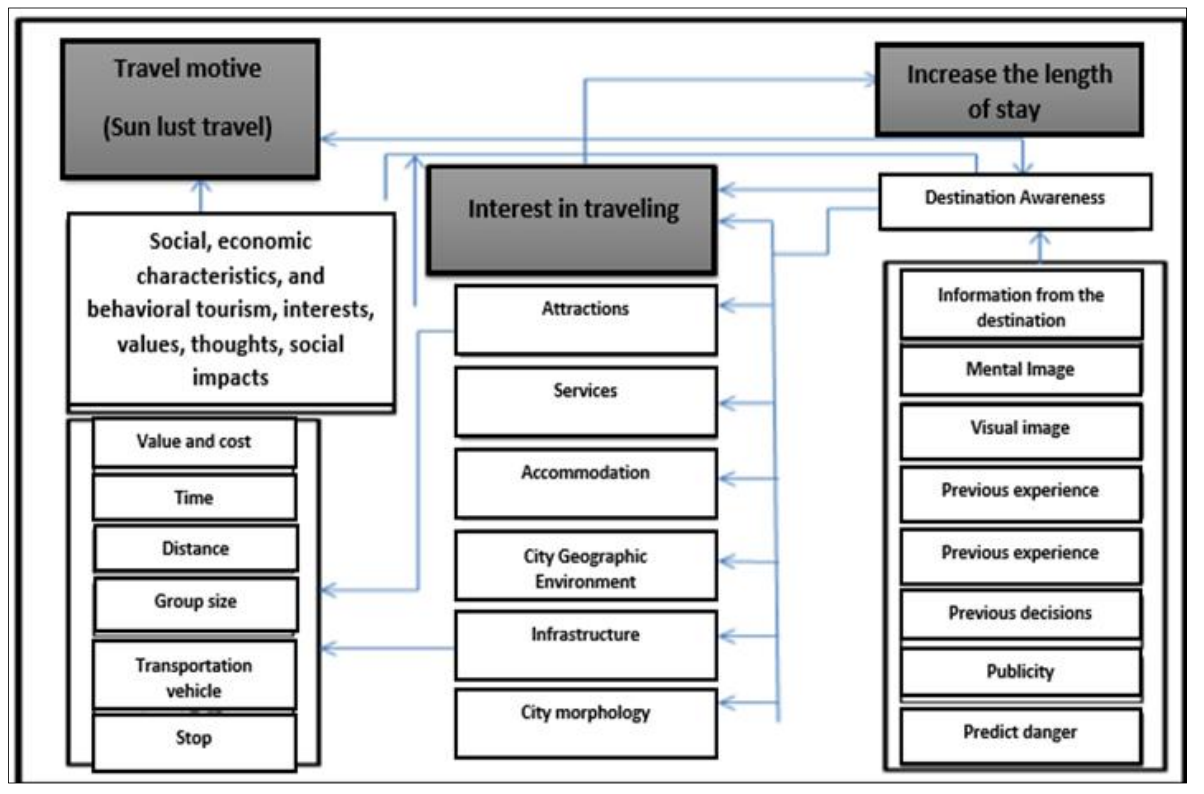

Fig. 2. Tourist behavioral pattern in the city

\section{METHODOLOGY}

A survey form designed to collect primary data from tourists from most hotels, inns, and tourist visit sites in Tehran. It is so important to know that ideas of the tourist about their trips and the destinations that they choose [23]. The respondent identified in the most tourist spotted areas. The organized questionnaire form distributed among the tourist. After that, clustering data and analysis in SPSS software to use it as shape file in GIS for producing maps. The secondary data was collected through available documents. Which means the secondary data had specific place; books, papers, reports, researches prepared by scholars, universities, urban planners, historical documents, Iran ministry of foreign affair, and ministry of cultural heritage and tourism. However not all data they had was suitable for this research but the data used based on objectives and hypotheses and with three characteristics reliability, suitability, and adequacy.

\subsection{Introduction of the Studied Case Area}

Tehran is the capital of the province and the capital of Iran. Agha Mohammad Khan is the founder of the Qajar dynasty in Nowruz 1200 AD. Ah After gaining power, he chose Tehran as the capital of Iran. History of Tehran follows the history of the city of Rey. The new Tehran was formed in the 16th century during Safavid dynasty.

Famous attractions of Tehran include Golestan Palace, Madrasa DaralFonoon, the beautiful and elegant monument of the National Garden Garden, Ghat Sadabad, Niavaran Palace, Jamaran, Tehran Market, Ancient Iran Museums, Islamic Iran, Anthropology, Carpet, Contemporary Art, Arts, Glassware The Library and Museum of Property and Wildlife and many other museums in Tehran are among its attractions. From the attractions of pilgrimage to the tomb of Hazrat Abdul Azim in Ray, Imamzadeh Saleh in Tajrish, Imamzadeh Davood in the north, and also the Imam Khomeini Shrine. 


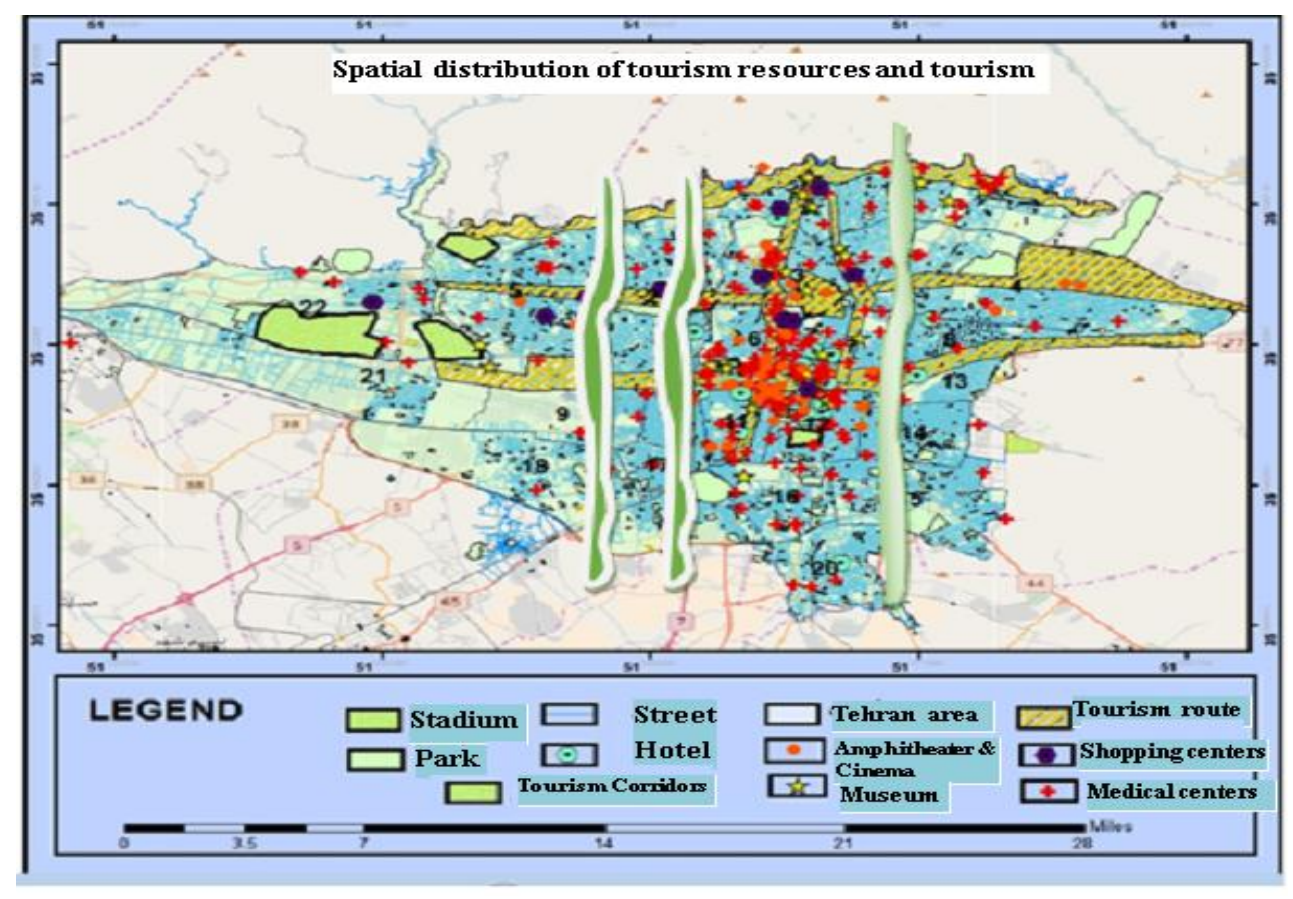

Fig. 3. Spatial distribution of Tehran tourist attraction

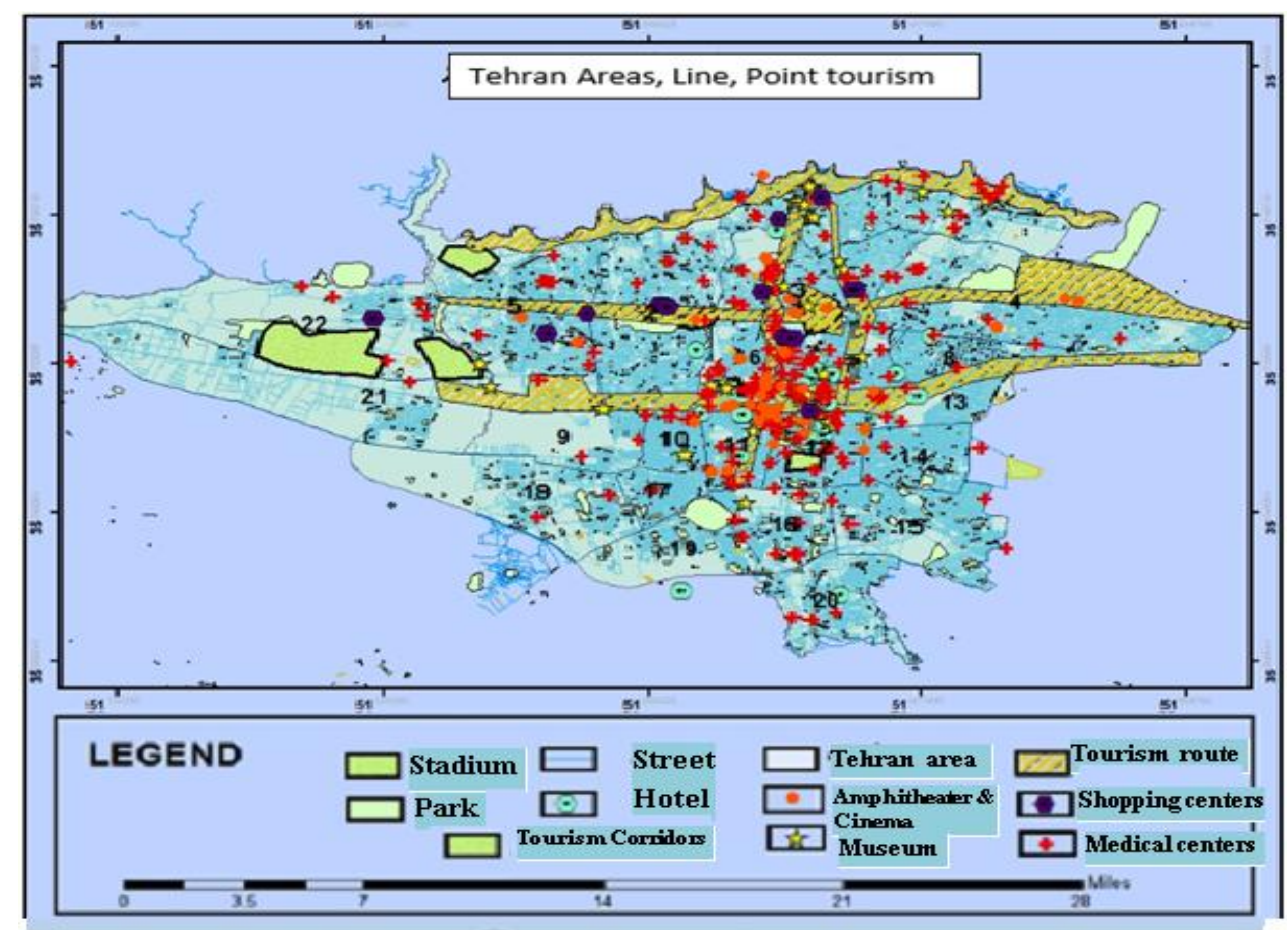

Fig. 4. Tehran tourist routes and city entrance gates

\section{ANALYSIS AND RESULTS}

As Table 2 shows that Iran and Tehran is very interesting for people below 50s years old.
Tourists between 28-17 years old rated over $47.4 \%$ out of total tourists. If we add people tourists in age group between 18 and 47 almost $73.6 \%$ of the tourist out of total tourist is in this 
age group. However, it seems there are less tourists above 50 s years old. Therefore, tourists in Tehran are young and Tehran is destination for young tourists. By the other words, can say Tehran is not suitable or is not attractive for middle age and old tourists.

\section{Table 2. Distribution of the age of tourists}

\begin{tabular}{lll}
\hline $\begin{array}{l}\text { Frequency } \\
\text { percentage }\end{array}$ & frequency & $\begin{array}{l}\text { Number of trips } \\
\text { to Tehran }\end{array}$ \\
\hline 17.7 & 68 & $18-27$ \\
47.4 & 182 & $28-37$ \\
11.5 & 44 & $38-47$ \\
5.7 & 22 & $48-57$ \\
11.5 & 44 & $58-67$ \\
4.2 & 16 & $68-77$ \\
2.1 & 8 & +77 \\
100.0 & 384 & Total \\
\hline
\end{tabular}

Table 3 shows Tehran is not a frequent place for people to have regular trips. Over $90 \%$ of the respondents have never been in Iran before. By combining Table 1 and Table 2 these group of young tourists, which rated the majority in Tehran, do not make the second trip and many of them come to Iran once.

Table 4 shows that the subway is more convenient for tourist to make their Urban trips in Tehran by over $45.4 \%$. Also, subway is the only way that they found and realized to escape from jammed streets in Tehran.
Table 3. Frequency distribution of respondents according to the number of trips to the destination

\begin{tabular}{lll}
\hline $\begin{array}{l}\text { Frequency } \\
\text { percentage }\end{array}$ & frequency & $\begin{array}{l}\text { Number of trips } \\
\text { to Tehran }\end{array}$ \\
\hline 90.6 & 348 & Never \\
5.7 & 22 & once \\
2.6 & 10 & Twice \\
1.0 & 4 & three times \\
100.0 & 384 & Total \\
\hline
\end{tabular}

Tehran's six entrances including 2 airports, 4 terminals and one railway. Imam Khomeini Airport $61.4 \%$ has the most tourist arrivals. According to the information given in Fig. 6, among the vehicles, tourists have used more than the metro. The least use of the tourists has been from the Internet Taxi. In Fig. 5 it shows that tourism behavioral pattern in Tehran is in the middle of Tehran to the north. The spatial distribution of tourist resources and destinations have formed the tourism spatial behavior pattern. The central part of Tehran is where the Tehran Bazar is located and many other buildings and urban designs from Qajar dynasty. Based ontime budget and Tehran tourism facilities the central part of Tehran is the most attractive place. It seems tourists in Tehran have not found anything or found less interesting things in the south, the west and the east parts of Tehran. Fig. 6 is the Tehran tourism spatial organization

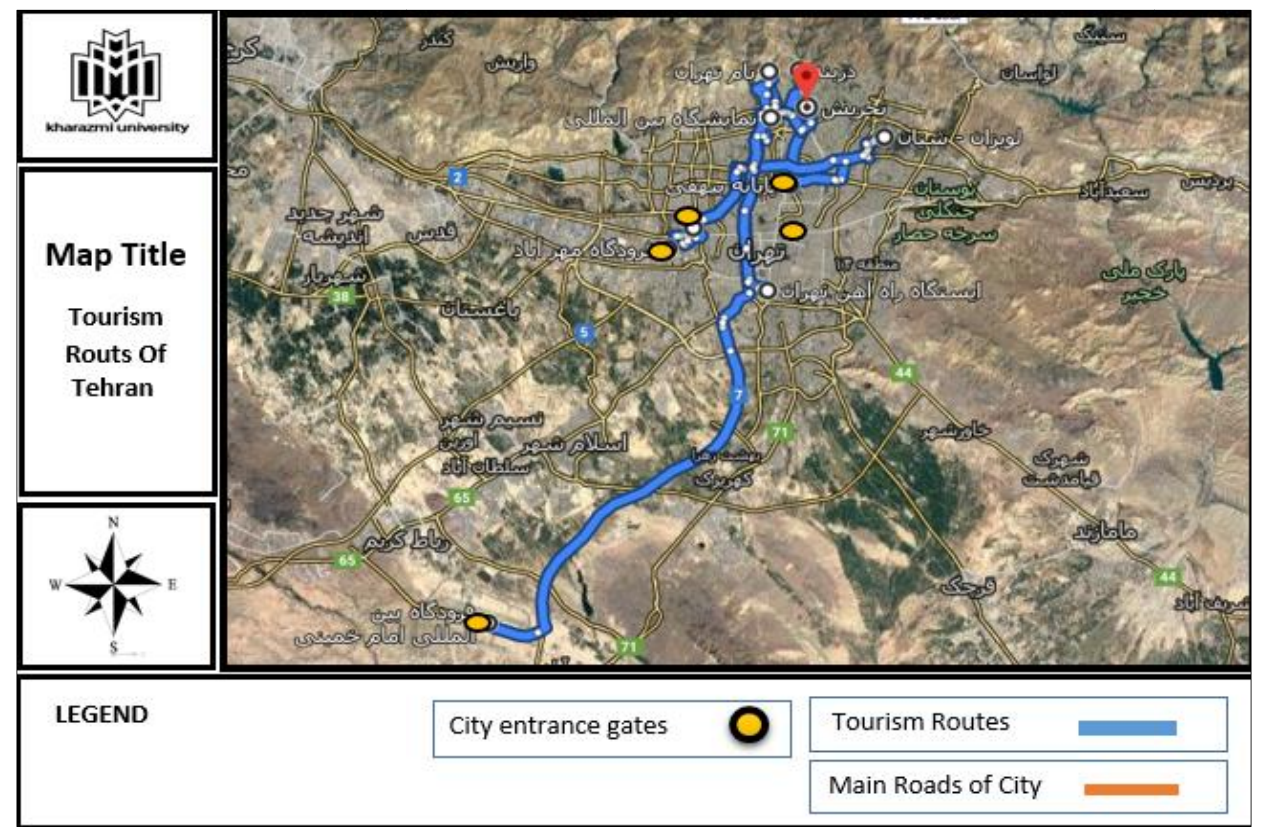

Fig. 5. Tehran. Line, point area tourism 


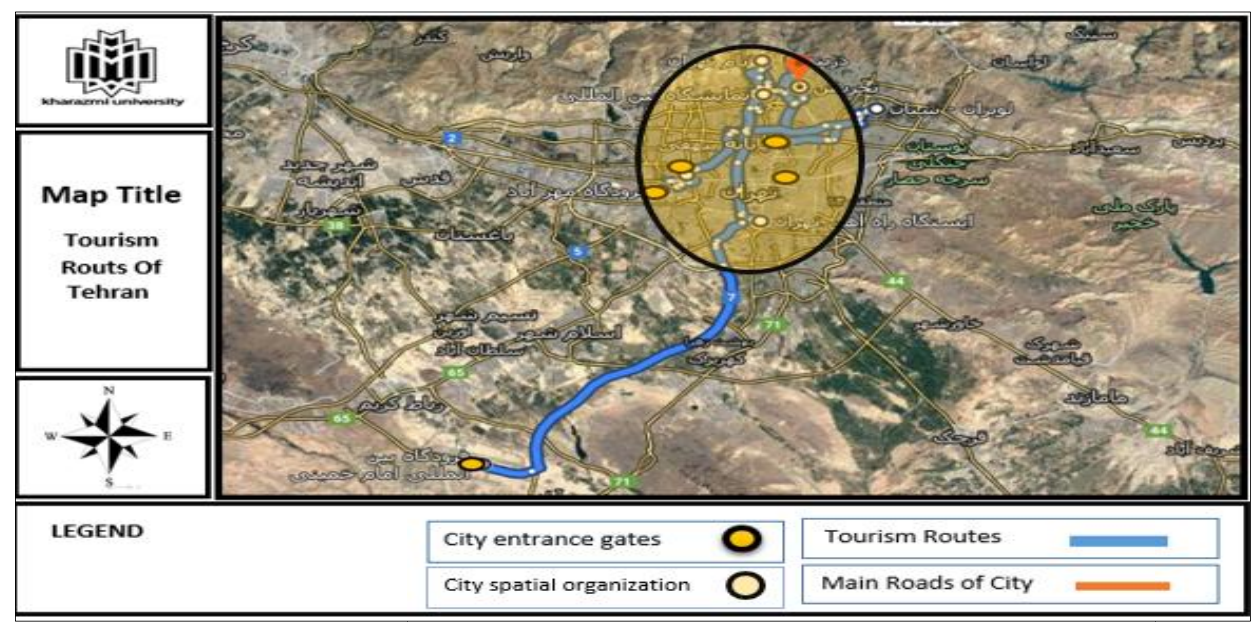

Fig. 6. Tehran City organization tourism

which is a starts from Tehran International Airport to central parts in Tehran and then spatters in district 12 in Tehran and moves to the north.

Table 4. Priority of tourists according to the use of transportation means

\begin{tabular}{llll}
\hline Moving device & Frequency & \% & Rank \\
\hline Subway & 220 & 45.4 & 1 \\
Taxi & 138 & 28.5 & 2 \\
Bus & 80 & 16.5 & 3 \\
Others & 28 & 5.8 & 4 \\
Internet Taxi & 18 & 3.7 & 5 \\
\hline
\end{tabular}

Figs. 3, 4, 5, and 6 show that the spatial pattern in Tehran is zonal in the central part of Tehran is and is linear in the north and the west part of Tehran. Since tourism geography is on from the behavior geography is very practical. After, Iran revolution and during the 8 years between Iran and Iraq the urban development in the East, West, and the north part of Tehran have neglected the necessity of urban tourism planning. Therefore, as figures show they are not poor urban tourism development made just the central part of Tehran attractive tourist destinations. In addition, the north part of Tehran enjoys a very good quality of weather in winter for skiing and summer mountaineering and trekking.

\section{CONCLUSION}

Iran is one of the most biodiversified and one of the historical countries in the world. Since neighboring countries, earn so much money from the tourism industry in comparison to Iran. The tourism geography and studies based on tourism geography can help to promote Iran tourism industry to the world. All these are hard to come by and need some painstaking efforts from university and institutes to the government. Tehran as the first tourist destination and capital city in Iran. There so many potentials in Iran (e.g. geographical, environmental, economic, historical, and cultural) which are unknown or are not really introduced to the tourists. The most important places are located in the central part of Tehran where district 12 is and for tourism, Bazar is one of the most important places to visit. The other places in Tehran have benefited from the Bazar. As a prime example, district 6 in Tehran is where some hotels and inns located to place the tourists. The other important place for tourists is the north part of Iran place like Shemiranat. The pleasant environment encourages tourists to visit the north part of Iran.

Based on the primary data analysis the tourism spatial pattern is depended on tourism resources. Where, the central part of Tehran is rich tourism destination the east, west, and south part of Tehran do not capacity to encourage make a trip in those areas. However, they have potentials that have never used. Furthermore, the tourism spatial behavior in the north part of Tehran is moving inside the routes while in central parts of Tehran tourist movements is zonal. The survey showed that Tehran's tourism spatial pattern is dependent on tourism resources. Most of the resources in the history area are located in the central part of Tehran. Therefore, the second hypothesis is based on the linearity of the behavioral spatial pattern of tourists is proved. Tourist spatial behavioral 
movements is Tehran is the same as the most jammed streets in Tehran and this pattern is fully focused on Tehran center. Therefore, it is important to pay attention on planning to ease the tourist's movement movements in Tehran. By the better words, Tehran urban planning and the district 12 in the central part in Tehran should address the basic tourist needs.

In the end, this study proved that there is not an integrated plan about tourism geography in Iran and in Tehran. Tourism in Tehran is very concentrated in the central city and the north part of Tehran. While Tehran has one of the most beautiful deserts the south part of Tehran. In the east part, Tehran has mountainous places without any notion or plan about the tourism industry. The west part of Tehran is the same even with Tehran Mall. If divide Tehran from north to the south in three main areas and from the west to the east, the central area from the north and the central area from the east to the west is the most important attractive place for tourists. The Azadi Square in the west and the Tehranpars Square in the east make the most important hub. This will become very important when joining to the other roads from the north part of Tehran to the South (e.g. Valiasr St and Chamran Highway) the other roads are not as important as these roads are.

\section{COMPETING INTERESTS}

Authors have declared that no competing interests exist.

\section{REFERENCES}

1. Williams S, Lew AA. Tourism geography: Critical understandings of place, space and experience. Routledge. 2014;271.

2. Najafi Asadollahi F, Rezazadeh A. Areas and concepts of tourism and tourism. Farahi Kotgan University Publication, First Edition, Tehran; 2016.

3. Nekooee Z, Karami M, Fakhari I. Assessment and prioritization of urban tourist attractions based on analytical hierarchy process (AHP) (a case study of Birjand, Iran). Journal of Applied Business and Economics. 2011;12(4):122-134.

4. Razavi K, Barta FT, Amini E. The effective spatial qualities on urban tourism in Iran focusing on social factors. In MATEC web of conferences. EDP Sciences. 2017;124: 06003.
5. Zhang K, Chen Y, Li C. Discovering the tourists' behaviors and perceptions in a tourism destination by analyzing photos' visual content with a computer deep learning model: The case of Beijing. Tourism Management. 2019;75:595608.

6. Niknami KA, Amirkhiz AC. A GIS technical approach to the spatial pattern recognition of archaeological site distribution on the eastern shores of Lake Urmia, Northwestern Iran. Proceedings of the International Archives of the Photogrammetry. Remote Sensing and Spatial Information Sciences. 2008;37:167-172.

7. Movahed A, Jafarpour Ghalehteimouri K. The importance of the concept and meaning of place in tourism geography. Journal of Tourism, Hospitality and Environment Management. 2019;4(16):0109.

8. Sharma P, Nayak JK. Testing the role of tourists' emotional experiences in predicting destination image, satisfaction, and behavioral intentions: A case of wellness tourism. Tourism Management Perspectives. 2018;28:41-52.

9. Dorta-Afonso D. Teaching organizational behavior in the bachelor of tourism through the case study method. Journal of Hospitality, Leisure, Sport \& Tourism Education. 2019;25:100204.

10. Su L, Hsu MK, Boostrom Jr. RE. From recreation to responsibility: Increasing environmentally responsible behavior in tourism. Journal of Business Research; 2019.

11. Seifolddini-Faranak $M$, Fard $S$, Ali $H$. Distribution and determining of tourist attractions and modeling of tourist cities for the city of Isfahan-Iran. Am. J. Econ. Bus. Admin. 2009;1:160-166.

12. Dabbagh KG. Spatial behavior in a Bahamian resort. Annals of Tourism Research. 1991;18(2):251-268.

13. Shaw Sh L, Bombom LS, Yu H. A spacetime GIS approach to exploring large Individual-based spatiotemporal datasets, transactions in GIS. 2008;12(4):425441.

14. Farajzadeh M. Geographic information system and its application in tourism planning. Fourth Edition, Publication, Tehran, Iran; 2013.

15. Shokouhi $H$, Movahed A. The article describes the patterns of tourism space in Isfahan city using the GIS system. Journal 
of the Faculty of Science and Human Literature (Moderator of Humanities), Tarbiat Modares University. 2002;6(4): Successive No. 27, Winter 81.

16. Bartosiewicz B, Pielesiak I. Spatial patterns of travel behaviour in Poland. Travel Behaviour and Society. 2019;15: 113-122.

17. Beeton S. Community development through tourism. Landlinks Press. Australia; 2006.

18. Xia J. Modelling the spatial-temporal movement of tourists. PhD Thesis, RMIT University, Australia; 2007.

19. Xia J, Zeephongsekul P, Packer D. Spatial and temporal modelling of tourist movements using Semi-Markov processes.
Tourism Management. 2011;32(4):844851.

20. Shokouhi H. New thoughts in geography philosophy. Ninth Edition, Gitashanzi Publications, Tehran. 1995;1.

21. Wagner HH, Fortin MJ. Spatial analysis of landscapes: Concepts and statistics. Ecology. 2005;86(8):1975-1987.

22. Antrop M. Background concepts for integrated landscape analysis. Agriculture, Ecosystems \& Environment. 2000;77(1-2): 17-28.

23. Asakura $Y$, Hato E. Tracking survey for individual travel behaviour using mobile communication instruments. Transportation Research, Part C. 2004;12(3/4):273291.

(c) 2020 Movahed and Ghalehteimouri; This is an Open Access article distributed under the terms of the Creative Commons Attribution License (http://creativecommons.org/licenses/by/4.0), which permits unrestricted use, distribution, and reproduction in any medium, provided the original work is properly cited.

Peer-review history:

The peer review history for this paper can be accessed here: http://www.sdiarticle4.com/review-history/53347 